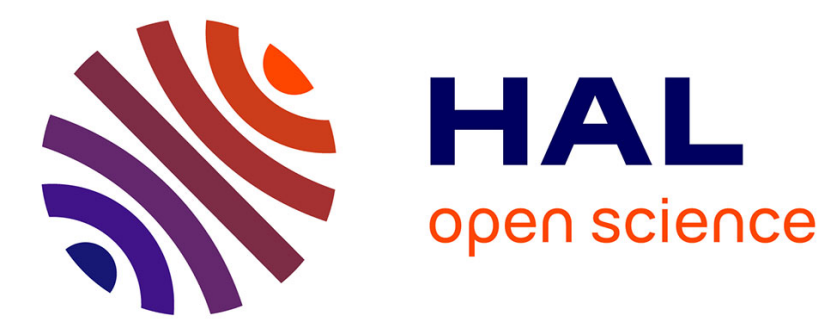

\title{
Neuropeptide Y receptors mediate ERK1/2 activation via transactivation of the IGF receptor
}

\author{
Sandra Lecat, Lazare Belemnaba, Jean-Luc Galzi, Bernard Bucher
}

\section{To cite this version:}

Sandra Lecat, Lazare Belemnaba, Jean-Luc Galzi, Bernard Bucher. Neuropeptide Y receptors mediate ERK1/2 activation via transactivation of the IGF receptor. Cellular Signalling, 2015, 27 (7), pp.12971304. 10.1016/j.cellsig.2015.03.016 . hal-02196924

\section{HAL Id: hal-02196924 \\ https://hal.science/hal-02196924}

Submitted on 29 Jul 2019

HAL is a multi-disciplinary open access archive for the deposit and dissemination of scientific research documents, whether they are published or not. The documents may come from teaching and research institutions in France or abroad, or from public or private research centers.
L'archive ouverte pluridisciplinaire HAL, est destinée au dépôt et à la diffusion de documents scientifiques de niveau recherche, publiés ou non, émanant des établissements d'enseignement et de recherche français ou étrangers, des laboratoires publics ou privés. 


\section{Neuropeptide $Y$ receptors mediate ERK1/2 activation via transactivation of the IGF receptor}

Sandra Lecat ${ }^{1 *}$, Lazare Belemnaba², Jean-Luc Galzi ${ }^{1}$, and Bernard Bucher ${ }^{2}$

${ }^{1}$ GPCRs, pain and inflammation team, UMR7242, CNRS-University of Strasbourg, LabEx Medalis, 67412 Illkirch, France. 300 Bvd Sébastien Brant, 67412, Illkirch Cedex, France

2 UMR 7213, CNRS/Université de Strasbourg, Laboratoire de Biophotonique et Pharmacologie, Faculté de Pharmacie, 74 route du Rhin, CS 60024, 67401 Illkirch, France

* Corresponding author: Sandra Lecat, GPCRs, pain and inflammation team, UMR7242, CNRS-University of Strasbourg, LabEx Medalis, 67412 Illkirch, France. 300 Bvd Sébastien Brant, 67412, Illkirch Cedex, France Phone: +33 3688547 38; Fax: +33 3688548 29; e-mail: sandra.lecat@unistra.fr 


\section{Abstract}

Neuropeptide $\mathrm{Y}$ binds to G-protein coupled receptors whose action results in inhibition of adenylyl cyclase activity. Using HEK293 cells stably expressing the native $Y_{1}$ neuropeptide $Y$ receptors, we find that the NPY agonist elicite a transient phosphorylation of the extracellular signal-regulated kinase $1 / 2$ (ERK1/2). We first show that ERK1/2 activation by the $\mathrm{Y} 1$ receptor is dependent on heterotrimeric $\mathrm{G}_{\mathrm{i} / \mathrm{o}}$ since it is completely inhibited by pre-treatment with pertussis toxin and it is internalization-independent since mutated $Y_{1}$ receptor which do not recruit -arrestins, exerted ERK1/2 activation to the same extent. We next show that this classical MAPkinase pathway activation, since inhibited by the MEK inhibitor U0126, is independent on calcium signaling at the $\mathrm{Y} 1$ receptor (no effect upon inhibition of phospholipase $C$, protein kinase $C$ or protein kinase $D$ ) but dependent on a $G$ mediated signalling pathway activating PI3-kinase. Although the Epidermal-Growth factor tyrosine receptor kinase inhibition did not influence NPY-induced ERK 1/2 activation, we show that the inhibition of Insulin Growth factor receptor IGFR by AG1024 completely block ERK1/2 activation by $\mathrm{Y} 1$ receptor. This $\mathrm{G}$-PI3K-AG1024sensitive pathway does not involve activation of IGFR through the release of a soluble ligand by metaloproteinases since it is not inhibited by marimastat. In addition, we found that a similar pathway, sensitive to wortmannin-AG1024 but insensitive to marimastat, was also found to be implicated in activation of ERK1/2 in HEK293 cells by endogenously expressed GPCRs coupled to Gq-protein (muscarinic M3 receptors) or coupled to Gs-protein (endothelin ETB receptors).

Keywords: neuropeptide Y; G protein-coupled receptor; extracellular-regulated protein kinase; human embryonic kidney, IGFR, beta-arrestin, marimastat, AG1024 
Introduction

Neuropeptide $\mathrm{Y}$ (NPY) is a widely distributed peptide in the central and peripheral nervous system (Berglund et al., 2003). The physiological functions of this neurohormone are mediated by a family of five receptors which belong to the class $A$ of the G-protein coupled receptors (GPCRs) and which are expressed in neuronal and non-neuronal tissues. Classically, signalling of GPCRs is mediated by receptor coupling to heterotrimeric $G$ proteins that activate a variety of downstream cellular effectors. The signalling pathway of the NPY family of receptors is known to be coupled to the Gai-protein, which leads to the inhibition of the adenylyl cyclase and inhibition of cAMP accumulation (Michel et al. 1998).

The classical paradigm of signalling via inhibition of adenylyl cyclase does not always adequately explain the full range of the effects of the activation of the NPY family receptors. Recent studies have shown that activation of the NPY receptors lead to cell proliferation, neurogenesis or gene transcription, via the phosphorylation of the extracellular signal regulated protein kinases 1 and 2 (Howell et al., 2005; Thiriet et al., 2011; Shimata et al., 2012). GPCRs can mediate ERK 1/2 activation by different mechanism, being able to induce activation of both $G$ protein-dependent and $G$ protein-independent signalling pathways.

Hence, growth promoting effects of GPCR stimulation have been shown to be mediated through transactivation of growth factor receptor tyrosine kinases (RTKs of epidermal growth factor (EGF), insulin growth factor (IGF), platelet-derived growth factor PDGF, fibroblast growth factor FGF, vascular endothelial growth factor VEGF and TrkA receptors, Wetzker and Böhmer 2003). Different mechanisms of transactivation have been described. It includes the extracellular release of RTK ligand by secretion or by shedding of a ligand through the processing of pre-ligand by plasma membrane metalloproteinases. Transactivation can also occurs inside the cell for example, activation of the c-Src-kinase is a general mechanism described, alternatively, it has been proposed to occur via direct molecular interaction between RTK and GPCRs or via inactivation of protein-tyrosine phosphatases that repress RTK (Prenzel et al. 1999, Pierce et al. 2001, Rozengurt 2007, Wetzker and Böhmer 2003, Oligny-Longpré et al. 2012). However, transactivation is not an essential 
requirement in the activation of the ERK1/2 signalling cascade induced by GPCR activation (Neve, 2005, Shah 2006).

During the past decade, evidences have emerged showing that a variety of GPCRs can also couple to other adaptor proteins independently of heterotrimeric G-protein (reviewed by DeFea, 2008; Shenoy and Lefkowitz, 2011). Among these transducers are the scaffolding proteins $\beta$-arrestin-1 and $\beta$-arrestin-2 which are cytosolic endocytic adaptors playing an important role in GPCRs desensitization, internalization and trafficking. Upon GPCR activation, they can also function as molecular mediators by acting especially on ERK1/2 signal transduction pathway (Shenoy et al., 2006). It is increasingly evident that $\beta$-arrestins can bind to MAP kinases and facilitate their activation (DeFea for review 2008?).

In previous studies, we have shown that, unlike NPY $Y_{2}$ receptors, NPY $Y_{1}$ receptors rapidly internalize through clathrin-coated pits and recycle (Gicquiaux et al. 2002, Ouedraogo et al., 2008). Upon stimulation by NPY, the endocytic mechanism involves cytosolic $\beta$-arrestins activation and translocation to the plasma membrane. Deletion of the carboxylterminal tail of the receptor $\left(\mathrm{Y}_{1} \Delta 42\right.$ receptor) or substitution of key putative phosphorylated residues by alanine in the C-terminal tail of the receptor ( $Y_{1}$ TDST-A receptor) abolish both internalization and $\beta$-arrestin activation Likewise, in the human NPY $Y_{2}$ receptor which does not internalize, no significant activation of $\beta$-arrestin activation was detected (Ouedraogo et al. 2008).

Therefore, the present study was undertaken in order to better understand the involvement of G-protein- and/or $\beta$-arrestins-mediated signalling in the ERK1/2 phosphorylation pathway in NPY receptor activation. Different aspects of NPYinduced ERK1/2 activation were evaluated by the use of the mutant receptors that do not recruit beta-arrestins and of specific inhibitors in order to sequentially investigate the downstream signalling mechanisms upon activation of the receptor. 
Material and methods

Cell culture, cDNA and treatments

Control and transfected HEK293 cells were cultured to $\sim 80 \%$ confluence in T-75 flasks in MEM with Earle's salt supplemented with $10 \%$ fetal calf serum, $2 \mathrm{mM}$ glutamine and 1\% antibiotics (penicillin/streptomycin) (Gicquiaux et al., 2002). For the specifics experiments, transfected HEK293 cells with the respective receptors were seeded in 6-well plates (200 000 - 300000 cells/well) in order to attain $70-80 \%$ confluence after 2 days of culture. Cells were then serum starved overnight (roughly $16 \mathrm{H}$ ) before activation with NPY with or without different inhibitors for different times as described in the individual experiments. The stimulation was terminated by aspirating the culture medium on ice and lysing the cells in $250 \mu \mathrm{L}$ of cold RIPA buffer (50mM Tris-Cl pH 7.4, 150mM NaCl, 1\% NP40, 0.25\% Na-deoxycholate) supplemented with EDTA-free anti-protease and anti-phosphatase cocktails.

cDNA of the human NPY $Y_{1}$ receptor was kindly provided by Prof. H. Herzog (Garvan Institute, Sydney, Australia). The cloning schemes for the different mutants of the native $Y_{1}$ receptor used in the present study were previously described (Ouedraogo et al., 2007; Lecat et al., 2011). All constructions were verified by sequencing and stably transfected cells were established by selective antibiotic selection.

SDS page and western blot analysis

Lysates were sonicated three times on ice using a Branson Sonifier at constant power, output $=2.5$, and continuous sonication for 1 second. After sonication, insoluble elements were cleared by centrifugation at maximum speed ( $14 k)$ for 5 minutes at $4^{\circ} \mathrm{C}$. Proteins concentration was determined using Bradford reagent. Homogenates of cell lysate were mixed with 4x laemmli buffer, denatured 5 min at $95^{\circ} \mathrm{C}$, loaded on a $12 \%$ SDS-PAGE gel $(20 \mu \mathrm{g} / \mathrm{lane})$. Protein samples were transferred to immobilon PVDF membranes. Membranes were blocked $1 \mathrm{~h}$ (using $5 \%$ nonfat dried milk in PBS, $\mathrm{pH} 7.2$, tween $0.1 \%$ ), probed overnight with rabbit (polyclonal) anti-ERK1/2 [pTpY185/187] phosphospecific antibody (1:5000, 
Invitrogeb, Camarillo, CA). The strips were thoroughly washed with PBS, Tween $0.1 \%$ then incubated $40 \mathrm{~min}$ with secondary antibody horseradish peroxidaseconjugated donkey anti rabbit diluted at 1/10 000. The immunoreactives bands were visualized using Immobilon western chemoluminescent HRP substrate detection reagents (Merck-Millipore) either with hyperfilm or LAS 4000 camera, bands were quantified using respectively either ImageJ or ImageQuant softwares (GEHealthcare). The data were normalized to the maximal phospho-ERK1/2 response for each set of experiment.

Antibodies desorbing and second antibodies incubation

Antibodies were stripped from the membrane strips by 3 incubations of $15 \mathrm{~min}$ in a desorbing solution (200 $\mathrm{mM} \mathrm{HCl}, 3 \%$ glycine). Membranes were washed thoroughly with PBS, Tween 0.1\%), then blocked $1 \mathrm{~h}$ using $5 \%$ nonfat dried milk in PBS, $\mathrm{pH} 7.2$, tween $0.1 \%$. Membrane strips were incubated overnight at $4^{\circ} \mathrm{C}$ with anti-ERK $1 / 2 \mathrm{pAb}$ antibody (1:10 000, Enzo Life Sciences, France). The strips were thoroughly washed with PBS, Tween $0.1 \%$ then incubated 40 min with secondary antibody horseradish peroxidase-conjugated donkey anti rabbit diluted at 1/10000. For each immunoblot, we used actin as loading control. Mouse monoclonal anti-actin clone C4 1/100 000 was from Merck-Millipore, HRP-goat anti-mouse from GE-Healthcare.

\section{Peptides and chemicals}

Human NPY was from Neosystem (France). PP2 and wortmannin were from Enzo Life Science (Villeurbanne, France). AG1478, AG1024, Gö6983, gallein and marimastat were from Tocris Bioscience (Bristol, UK). U73122, U0126, pertussis toxin (PTX) were from Sigma-Aldrich (L'Isle d'Abeau Chesnes, France). 
Results

\section{NPY $Y_{1}$ receptors mediate ERK1/2-phosphorylation via a Gi-dependent pathway.}

To determine the temporal pattern of ERK1/2 activation mediated by NPY, we examined the kinetic of ERK1/2 phosphorylation following stimulation by NPY in $Y_{1}$ receptors expressing HEK293 cells. For this time-course study cells were incubated with 100 nM NPY for several time-points. Kinetic analysis by western-blot revealed that NPY treatment induced a rapid phosphorylation of ERK1/2 with a maximal activity at $5 \mathrm{~min}$ (Fig. 1A). The return to almost basal levels of phosphorylation was achieved by $20 \mathrm{~min}$. NPY induced a concentration-dependent increase in levels of ERK1/2 phosphorylation in cells expressing the human $Y_{1}$ receptor (Fig. 1B) with an $\mathrm{EC}_{50}$ of $0.3 \mathrm{nM}$. In order to assess the role of Gi/o proteins in NPY mediated ERK1/2 phosphorylation, the effect of selective inhibition of Gi-dependent signalling in human $\mathrm{Y}_{1}$ receptor expressing cell lines was examined. PTX pre-treatment, concentrationdependently, inhibited ERK1/2 phosphorylation induced by $100 \mathrm{nM}$ NPY indicating use of Gi/o proteins in the ERK signalling pathway (Fig. 1C). The inhibitor of the mitogen-activated protein (MAP) kinase/ERK kinase (MEK), U0126, abolished in a concentration dependent manner, ERK1/2 phosphorylation in response to $300 \mathrm{pM}$ NPY indicating a conventional mechanism of ERK1/2 activation in the NPY $Y_{1}$ receptor (Fig. 1D).

\section{NPY $Y_{1}$ and $Y_{2}$ receptors mediate ERK1/2-phosphorylation via an internalization-independent pathway.}

To test the role of beta-arrestins in MAPkinase signaling at the level of activated NPY receptors, we have analysed the signaling induced by receptors that do not recruit beta-arrestins such as NPY $Y_{2}$ receptors and mutants of $Y_{1}$ receptors (Ouedraogo et al. 2008).

Kinetic analysis by western-blot revealed that NPY treatment induced a rapid phosphorylation of ERK1/2 by $\mathrm{Y}_{2}$ receptors with a lower intensity as compared to phosphorylation of ERK1/2 by wild-type $Y_{1}$ receptors (Fig. 2A). It also peaked with a maximal activity at $10 \mathrm{~min}$ instead of $5 \mathrm{~min}$ (Fig. 2B). Exposure of cells expressing the human $Y_{2}$ receptor resulted in a concentration-dependent increase in ERK1/2 phosphorylation with an $\mathrm{EC}_{50}$ value of $10 \mathrm{nM}$ (Fig. 2C). PTX pre-treatment, 
concentration-dependently inhibited ERK1/2 phosphorylation induced by $100 \mathrm{nM}$ NPY indicating use of Gi/o proteins in the ERK signalling pathway (Fig. 2D).

Similarly, kinetic analysis by western-blot revealed that NPY treatment induced a rapid phosphorylation of ERK1/2 with a maximal activity at 5 min for cells expressing the human $\mathrm{Y}_{1} \Delta 42$ and $\mathrm{Y}_{1}$ TDST-A receptors (Fig3A and 3B respectively). Thus, $\mathrm{Y} 1$ mutants receptors that do not recruit beta-arrestins and do not internalized trigger MAPkinase activation to the same extent as wild-type receptors ruling out a mechanism of activation mediated by platforms of beta-arrestins bound to $\mathrm{Y} 1$ receptors in the endosomes.

NPY $Y_{1}$ receptors mediate ERK1/2-phosphorylation via a calcium-independent pathway.

NPY is also able to stimulate intracellular $\mathrm{Ca}^{2+}$ increases via PKC-dependent pathways including the upstream signalling molecules, phospholipase C (PLC) and phospholipase D (PLD). We evaluated the possible involvement of these signalling pathways in NPY-mediated ERK1/2 activation by $Y_{1}$ receptors. The results showed that the PKC inhibitor Gö6983 was not able, at the concentrations tested, to block the ERK1/2 phosphorylation induced by 300 pM NPY (Fig. 4B). Likewise, the PLC inhibitor U73122; an inhibitor of PLC activation by G-protein-linked receptors (Thompson et al) or the PLD inhibitor FIPI were both unable to block ERK1/2 activation (Fig. 4A and not shown). Therefore, these results clearly indicate that activation of the human NPY $Y_{1}$ receptor induces ERK1/2 activation via a PKC- and PLC-, PLD-independent pathway suggesting that calcium-dependent signalling pathways do not play an important role in this process.

\section{NPY $Y_{1}$ receptors mediate ERK1/2-phosphorylation via a PI3Kinase-dependent} pathway.

We next assessed for the $Y_{1}$ receptor, the contribution of $G \beta \gamma$ subunits to the $E R K 1 / 2$ activation by using gallein which has been shown to selectively inhibit the interactions between $\mathrm{G} \beta \gamma$ and effectors proteins (Lehmann et al. 2008). Pre-treatment with gallein inhibited ERK1/2 activation in a concentration-dependent manner (Fig. 4C).

Earlier studies have shown that the phosphoinositide 3-kinase (PI3K) is a signalling intermediate of the $\beta \gamma$-subunit of $\mathrm{G}_{\mathrm{i}}$-mediated MAP kinase activation (Hawes et al. 
1996, Yart et al. 2003). We have pre-treated cells expressing the human NPY $Y_{1}$ receptor for $1 \mathrm{~h}$ with increasing concentrations of wortmaninn, an inhibitor of class I, II and III PI3Ks. Phosphorylation of ERK1/2 by 300 pM NPY was concentration dependently inhibited by the PI3K inhibitor (Fig. 4D) indicating that the signalling pathway conducting to ERK1/2 activation is PI3K-dependent.

Src-family tyrosine kinase activity has also been suggested to be involved in ERK1/2 signalling downstream of activated GPCR receptors via RTK-transactivation upstream of PI3K (Luttrell et al. 1996, Wetzker and Bohmer 2003, Jeong et al. 2008). To test whether Src kinase is involved in ERK1/2, the Src inhibitor PP2 was used. Cell expressing the human $Y_{1}$ NPY receptor were pre-incubated for $1 \mathrm{~h}$ with increasing concentrations of PP2 and stimulated with 300 pM NPY. At all concentrations tested, PP2 failed to inhibit ERK1/2 phosphorylation in response to NPY activation (Fig. 4E). Together, the results indicate that upon activation of $Y_{1}$ receptors, Src-family tyrosine kinase stimulation is not implicated in ERK1/2 activation.

To assess the role of EGF receptor (EGFR) transactivation in the NPY-induced ERK1/2 phosphorylation, cells expressing the human $\mathrm{Y}_{1}$ receptor were pre-treated with AG1478, an EGFR inhibitor. After $1 \mathrm{~h}$ pre-treatment with various concentration of AG1478, we observed no effect (Fig. 4F) on ERK1/2 phosphorylation in response to 300pM NPY, suggesting that it is unlikely for EGFR to be involved in NPYmediated activation of ERK1/2.

\section{NPY $Y_{1}$ receptors mediate ERK1/2-phosphorylation via an IGFR-dependent but metalloproteinase-independent pathway.}

The hypothesis of transactivation of RTKs was further explored. Cells expressing the human $Y_{1}$ receptor were pre-treated with AG1024, an specific IGFR inhibitor. After 1 h pre-treatment with various concentration of AG1024, we observed a dosedependent inhibition (Fig. 5A) on ERK1/2 phosphorylation in response to $300 \mathrm{pM}$

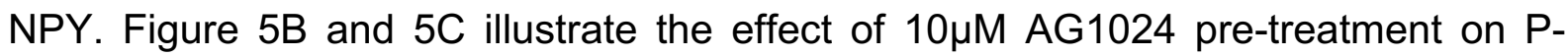
ERK1/2 as compared with vehicle treated cells, with a representative western blot (5B) and the quantification (5C).

The metalloproteinase inhibitor marimastat, that has a large spectrum of action on both matrix-metalloproteinases MMPs but also ADAMs (A Disintegrin And metalloproteases, Roghani et al. 1999), was recently shown to inhibit the 
transactivation of IGFR receptors in HEK293 cells triggered by the Gs-coupled V2 vasopressin receptor and by the Go/Gq-coupled platelet-activating factor PAF receptor (Oligny-Longpré et al. 2011). In order to test whether NPY induces the shedding of an IGFR ligand through the processing of pre-ligand by plasma membrane metalloproteinases, HEK293 cells expressing the human $Y_{1}$ receptor were pre-treated for $1 \mathrm{~h}$ with $10 \mu \mathrm{M}$ marimastat. We did not observe any inhibition on ERK1/2 phosphorylation in response to 300pM NPY (Fig. 5D). In conclusion, the IGFR is transactivated by $Y_{1}$ receptors in HEK293 cells via a Gi/Gbeta-gammaPI3Kinase-dependent mechanism without the release of a soluble ligand for IGFR.

\section{A similar pathway to ERK1/2 by GPCRs in HEK293 cells}

We and other have demonstrated that ERK1/2 is phosphorylated by a number of endogenously expressed GPCRs in HEK293 cells (Michel et al. 2014) and we wanted to address the relative universality of the present pathway. We found that wortmannin, AG1024 but not marimastat were inhibiting the ERK1/2 phosphorylation induced at 5 minutes by the Gq-coupled muscarinic M3 receptor (Figure 6A-D, B-E and C-F respectively) and by the Gs-coupled Adenosine receptor as well (Figure 6G, $\mathrm{H}$, I respectively). This suggests that the MAPkinase pathway governed by $\mathrm{Y}_{1}$ receptor is also used by endogenously expressed GPCRs in HEK293 cells. 


\section{Discussion}

In HEK293 cells stably expressing the wild-type NPY $Y_{1}$ receptor, activation of this receptor is able to induce a rapid and transient ERK1/2 phosphorylation. The signalling pathway conducting to this activation involves Galphai and $G \beta / \gamma$ protein subunits. For the first time, we show that MAPkinase activation by $\mathrm{Y} 1$ receptors is an internalization-independent pathway and that this receptor can transactivate the IGFR receptor (Figure 7A). We finally show that a similar mechanism of MAPkinase activation through a PI3Kinase-dependent but metalloprotease-independent transactivation of IGFR is used by endogenously expressed Gq- and Gs-coupled receptors in HEK293 cells.

A very interesting mechanism of activation of MAPkinases by GPCRs through transactivation of IGFR was dissected in HEK293 cells recently. It constituted one of the first description of transactivation of IGFR leading to MAPkinase activation by a GPCR (Oligny-Longpré et al. 2011). In this study, the Gs-coupled V2 receptor overexpressed in HEK293 cells was found to mediate an heterotrimeric G-proteinindependent transactivation of IGFR independently of PI3kinases (insensitive to wortmannin Charest et al. 2007). It occurs via the release by plasma membrane metalloproteinases of an unidentified soluble agonist of IGFR (inhibition by marimastat). This pathway was dependent on c-Src activation (inhibiton by PP2) upstream of IGFR while beta-arrestins were necessary downstream of IGF receptor to trigger MAPkinase activation but not downstream of the activated GPCR themselves (Figure 7B). In a more complex experimental set-up in which EGF receptors were desensitized in HEK293 cells, Gi-coupled-delta-opioid receptors were also found to trigger MAPkinase activation through transactivation of the IGFR via the shedding of an IGF-1-like peptide (Eisinger and Ammer 2010).

The pathway that we are describing now is different than the one described for MAPkinase activation via the vasopressin V2 receptor by several aspects:

MAKinases activation by NPY Y1 receptor is definitively G-protein dependent, PTX and gallein (Lehmann et al.), respectively specific inhibitors of Galphai and Gbetagamma subunits, blocking completely ERK1/2 phosphorylation in a concentrationdependent manner. The pathway that we have unravelled is also clearly insensitive to the c-Src inhibitor PP2 or to the metalloprotease inhibitor marimastat while it is sensitive to wortmannin. 


\section{IGFR transactivation by NPY Y1 receptors}

On the other hand, we are confirming the previous results that transactivation of IGFR by several GPCRs leads to MAPkinase activation. We demonstrated it using the AG1024 inhibitor, that was one of the few uni-specific kinase inhibitors identified in a recent comprehensive assay of kinase inhibitor selectivity (Anastassiadis et al. 2011). In this same analysis, however, AG1024 was among the 17 uni-specific compounds that inhibited other kinases more potently than the kinases they were intended to target. Indeed, the serine/threonine kinase RIPK2 (Receptor-interacting kinase2) was identified as a much more sensitive target of AG1024. Although RIPK2 becomes phosphorylated upon activation of the Gq-coupled Angiotensin AT1 receptor as described in a recent phosphoproteomic analysis (Christensen et al. 2010), this kinase is an activator of the NF-KB pathway and is a component of signaling in immune responses (ref). Since there is so far no indication that RIPK2 could trigger MAPkinase activation, we rather favour the interpretation that IGFR is the target of AG1024 in our study.

Insulin or IGF ligand binding to the IGFR can activate MAPkinases (Luttrell et al. 1995, Kurihara et al. 2000, Kuemmerle and Murphy 2001). We have observed it in our previous signaling study in HEK293 cells (Michel et al. 2014). The mechanism of ligand-dependent MAPkinase activation of IGFR is not yet clearly determined : betaarrestins have been proposed to play a role (Oligny-Longpré et al. 2011). Indeed beta-arrestins can serve as platforms to recruit several effectors of the MAPkinase pathway (DeFea for review 2008) and beta-arrestin 1 has been found necessary for MAPkinase activation via the IGFR (Girnita et al. 2007). In this line of thinking, a new concept has emerged in which it is proposed that RTK themselves can transactivate GPCRs, therefore it is not clear whether beta-arrestins are direcly interacting with the RTKs or whether interaction with another GPCR is needed in this MAPkinase activation mechanism (Delcourt et al. 2007).

We have not adressed the requirement of beta-arrestins downstream of IGFR because the mechanism of transactivation of IGFR by the Gi-coupled NPY Y1 receptor seems to occur via a ligand-independent activation of IGFR (independent of c-Src and metalloproteases). On the other hand, we have clearly established that recruitment of beta-arrestins and internalization of the NPY Y1 receptor are not necessary for Erk1/2 activation. Two mutants of the NPY Y1 receptor that upon NPY activation are unable to bind beta-arrestins, to activate beta-arrestins and to 
internalize into clathrin-coated pits, were unaltered in their amplitudes and kinetics of Erk1/2 phosphorylation (Ouedraogo et al. 2008).

It has been observed in several studies, that in the Gi-coupled receptor and $\mathrm{G} \beta \gamma$ mediated MAPkinase signalling pathway, inhibitors of the phosphoinositide 3-kinases (PI3Ks) attenuated the MAP kinase activation demonstrating the requirement of PI3Ks in the intracellular signal transduction pathway through which GPCRs might be able to activate the expression of transcription factors involved in cell growth and proliferation (Hawes et al. 1996).

In our present study a wortmannin-sensitive $\mathrm{G} \beta / \gamma$-stimulated PI3K activity was required for MAP kinase signalling pathway. Studies indicate that the PI3K- $\gamma$ isoform of the PI3K family, that is directly activated by $\mathrm{G} \beta / \gamma$, regulates the signalling from GPCRs (Lopez llasaca et al. 1997) especially that of chemokines and chemo attractant receptors (Deane, Procko, Del Prete Delgado-Martin, 2011). But PI3K- $\beta$ has also been shown to be regulated by $G \beta / \gamma$ (Yart et al. 2003). The mechanism of transactivation of IGFR by NPY Y1 receptor could thus be similar to the one triggered by the lysophosphatidic acid LPA receptors through transactivation of the EGFR observed in Vero cells (Yart et al. 2003). Indeed, in their study, Yart and colleagues have proposed that PI3K integrates two separate signals from the activated GPCR, both through direct interaction with the released $G \beta / \gamma$ subunits and at the level of transactivation of the RTK contributing to an amplification of the MAPkinase pathway. In effect, amplification was confirmed using a phosphoproteomics approach, direct EGFR activation of the cells gave rise to weaker phosphorylations of sites phosphorylated by transactivation of the EGFR upon LPA stimulation (Schreiber et al. 2010).

\section{The mechanisms of NPY activation of the MAPkinase pathway described.}

While we are the first to propose a transactivation of IGFR and to establih an internalization-independent mechanism, the MAPkinases activation triggered by NPY Y1 receptor that we are describing, is in agreement with previous studies: PTX and wortmannin sensitivity was observed (Keffel et al. 1999, Mullins et al. 2002. Interestingly, a recent investigation has proposed that neuroproliferative effect of NPY in postnatal hippocampal precursor cells is mediated by a MAPkinase pathway occuring downstream of intracellular nitric oxide production, cGMP and the cGMPdependent protein kinase PKG activation (Alvaro et al. 2008, Cheung et al. 2012). 
Further studies are required to investigate the relationship between transactivation of IGFR and nitric oxide production, as was studied for example in the case of angiotensin receptor transactivation of EGFR (Wang et al. 2000) or bradykinin B2 receptor transactivation of vascular endothelial growth factor (Thuringer et al. 2002).

Acknowledgements: The work was in part supported by the CNRS. We thank Professors $\mathrm{H}$. Herzog for NPY receptor plasmids. Dr. Jeremy Garwood is acknowledged for his critical reading of the manuscript. 


\section{References}

Anastassiadis et al. 2011

Comprehensive assay of kinase catalytic activity reveals features of kinase inhibitor selectivity

Theonie Anastassiadis1, Sean W Deacon2, Karthik Devarajan1, Haiching Ma2 \& Jeffrey R Peterson1 Nature Biotechnology . 29 :1039-1045

M.M. Berglund, P.A. Hipskind, D.R. Gehlert. Recent developments in our understanding of the physiological role of PP-fold peptide receptor subtypes. Exp. Biol. Med. 228 (2003) 217-24.

J.A. Deane, D.A. Fruman. Phosphoinositide 3-kinase: diverse roles in immune cell activation. Annu. Rev. Immunol. 22 (2004) 563-598.

K. DeFea. -arrestins and heterotrimeric G-proteins: collaborators and competitors in signal transduction. Br. J. Pharmacol. 153 (2008) S298-S309.

C. Delgado-Martin, C. Escribano, J.L. Pablos, L. Riol-Blanco, J.L. RodriguezFernández. Chemokine CXCL12 uses CXCR4 and a signaling core formed by bifunctional Akt, extracellular signal-regulated kinase (ERK)1/2, and mammalian target of rapamycin complex 1 (mTORC1) proteins to control chemotaxis and survival simultaneously in mature dendritic cells. J. Biol. Chem. 286 (2011) 37222-37236

A. Del Prete, W. Verni, E. Dander, K. Otero, L. Barberis, W. Luini, S. Bernasconi, M. Sironi, A. Santoro, C. Garlanda, F. Faccheti, M.P. Wymann, A. Vecchi, E. Hirsch, A. Mantovani. S. Sozzani. Defective dendritic cell migration and activation of adaptative immunity in PI3K -deficient mice. EMBO J. 23 (2004) 3505-3515.

Christensen GL, Kelstrup CD, Lyngso C, Sarwar U., Bogebo R, Sheikh SP, Gammeltoft S, Olsen JV, Hansen JL. (2010). Quantitative phosphoproteomics dissection of sevent-transmembrane receptor signaling using full and biased agonists. Mol. Cell. Proteomics. 9(7):1540-53.

Gicquiaux H, Lecat S, Gaire M, Dieterlen A, Mély Y, Takeda K, Bucher B, Galzi JL. (2002). Rapid internalization and recycling of the human neuropeptide $Y Y(1)$ receptor. J Biol Chem. 2002 Feb 22;277(8):6645-55. Epub 2001 Dec 7.

B.E. Hawes, L.M. Luttrell, T. van Biesen, R.J. Lefkowitz. Phosphatidylinositol 3kinase is an early intermediate in the $G$-mediated mitogen-activated proteinkinase signaling pathway. J. Biol. Chem. 271 (1996) 12133-12136.

Howell OW ${ }^{1}$, Doyle K, Goodman JH, Scharfman HE, Herzog H, Pringle A, BeckSickinger AG, Gray WP. (2005). Neuropeptide $Y$ stimulates neuronal precursor proliferation in the post-natal and adult dentate gyrus. J Neurochem. 93(3):560-70.

Lecat S, Ouédraogo M, Cherrier T, Noulet F, Rondé P, Glasser N, Galzi JL, Mely Y, Takeda K, Bucher B. (2011). Contribution of a tyrosine-based motif to cellular trafficking of wild-type and truncated NPY Y(1) receptors. Cell Signal. 23(1):228-38.

A. Levitzki, A. Gazit. Tyrosine kinase inhibition: an approach to drug development. Science 267(1995) 1782-1788. 
M.C. Michel, A. Beck-Sickinger, H. Cox, H. Doods, H.N. Herzog, D. Larhammar, R. Quirion, T. Schwartz, T. Westfall. XVI. International Union of pharmacology recommendations for the nomenclature of neuropeptide $Y$, peptide $Y Y$, and pancreatic polypeptide receptors. Pharmacol. Rev 1998) 143-150.

Michel G, Matthes HW, Hachet-Haas M, El Baghdadi K, de Mey J, Pepperkok R, Simpson JC, Galzi JL, Lecat S. (2014) Plasma membrane translocation of REDD1 governed by GPCRs contributes to mTORC1 activation. J Cell Sci. 127:773-787.

K.A. Neve. Double feature at the signalplex. Mol. Pharmacol. 68 (2005) 275-278.

Oligny-Longpré $\mathrm{G}^{1}$, Corbani M, Zhou J, Hogue M, Guillon G, Bouvier M. (2012). Engagement of $\beta$-arrestin by transactivated insulin-like growth factor receptor is needed for V2 vasopressin receptor-stimulated ERK1/2 activation. Proc Natl Acad Sci U S A. 109:E1028-37.

Ouedraogo M, Lecat S, Rochdi MD, Hachet-Haas M, Matthes H, Gicquiaux H, Verrier S, Gaire M, Glasser N, Mély Y, Takeda K, Bouvier M, Galzi JL, Bucher B. (2008). Distinct motifs of neuropeptide $Y$ receptors differentially regulate trafficking and desensitization. Traffic. 9(3):305-24.

K.L. Pierce, L.M. Luttrell, R.J. Lefkowitz. New mechanisms in heptahelical receptor signaling to mitogen activated protein kinase cascades. Oncogene, 20 (2001) 15321539.

N. Prenzel, E. Zwick, H. Daub, M. Leserer, R. Abraham, C. Wallasch, A. Ullrich. EGF receptor transactivation by G-protein-coupled receptors requires metalloproteinase cleavage of proHB-EGF. Nature 403 (1999) 884-888.

E. Procko, S.R. McColl. Leucocytes on the move with phosphoinositide 3-kinase and its downstream effectors. Bioessays, 27 (2005) 153-163.

Monireh Roghani, J. David Becherer, Marcia L. Moss, Ruth E. Atherton, Hediye Paul Erdjument-Bromage, Joaquin Arribas, R. Tempst and Carl P. Blobel

Metalloprotease-Disintegrin MDC9: Intracellular Maturation and Catalytic Activity

J. Biol. Chem. 1999, 274:3531-3540.

E. Rozengurt. Mitogenic signaling pathways induced by $\mathrm{G}$ protein-coupled receptors. J. Cell. Physiol. 213 (2007) 589-602.

B.H. Shah, A. Neithardt, D.B. Chu, F.B. Shah, K.J. Catt. Role of EGF transactivation in phosphoinositide 3-kinase-dependent activation of MAP kinase by GPCRs. J. Cell. Physiiol. 206 (2006) 47-57.

Shenoy SK, Lefkowitz RJ. (2011). $\beta$-Arrestin-mediated receptor trafficking and signal transduction. Trends Pharmacol Sci. 2011

Shenoy SK ${ }^{1}$, Drake MT, Nelson CD, Houtz DA, Xiao K, Madabushi S, Reiter E, Premont RT, Lichtarge O, Lefkowitz RJ. (2006). beta-arrestin-dependent, G proteinindependent ERK1/2 activation by the beta2 adrenergic receptor. J Biol Chem. 281(2):1261-73.

Shimada $K^{1}$, Ohno Y, Okamatsu-Ogura Y, Suzuki M, Kamikawa A, Terao A, Kimura K. (2012). Neuropeptide $Y$ activates phosphorylation of ERK and STAT3 in stromal 
vascular cells from brown adipose tissue, but fails to affect thermogenic function of brown adipocytes. Peptides. 34(2):336-42.

Schreiber TB, Mausbacher N, Kéri G, Cox J, Daub H. (2010) An integrated Phosphoproteomics Work Flow reveals extensive network regulation in early lysophosphatidic acid signaling. Mol. Cell. Proteomics. 9(6): 1047-62.

Thiriet N, Agasse F, Nicoleau C, Guégan C, Vallette F, Cadet JL, Jaber M, Malva JO, Coronas V. (2011). NPY promotes chemokinesis and neurogenesis in the rat subventricular zone. J Neurochem. 116(6):1018-27.

Dominique Thuringerł, Laurence Maulon, and Christian Frelin

Rapid Transactivation of the Vascular Endothelial Growth Factor Receptor KDR/FIk-1 by the Bradykinin B2 Receptor Contributes to Endothelial Nitric-oxide Synthase Activation in Cardiac Capillary Endothelial Cells*

Published, JBC Vol. 277, No. 3, Issue of January 18, pp. 2028-2032, 2002

GABAB Receptor Activation Protects Neurons from Apoptosis via IGF-1 Receptor Transactivation

Haijun Tu,1* Chanjuan Xu,1* Wenhua Zhang,1 Qiuyao Liu,1 Philippe Rondard,2 Jean-Philippe Pin,2 and Jianfeng Liu1 The Journal of Neuroscience, January 13, $2010 \cdot 30(2): 749-759 \cdot 749$

Wang, D, Yu, X, Cohen RA, Brecher P (2000). Distinct effects of N-acetylcysteine and nitric oxide on angiotensin II-induced epidermal growth factor receptor phosphorylation and intracellular $\mathrm{Ca}(2+)$ levels. J Biol Chem 2000; 275: $12223-$ 12230. 
Figures legends

\section{Figure 1}

NPY induces ERK1/2 activation in a time- and concentration-dependent manner in human $Y_{1}$ receptor (O) expressing HEK293 cells. (A) Time course of ERK1/2 phosphorylation following NPY stimulation. Serum-starved HEK293 cells expressing the NPY $Y_{1}$ receptor were incubated with NPY $(100 \mathrm{nM})$ for the indicated times. A representative western blot is displayed together with densitometry analyses of ERK1/2 activation normalized to the maximal response at 5 minutes. In all blots, 20 $\mu \mathrm{g}$ of total protein were analyzed. ERK1/2 phosphorylation was determined using anti-phospho-ERK1/2 antibody. Anti-total-ERK1/2 and anti-actin antibodies were used to control protein concentrations. (B) Concentration-dependence of ERK1/2 phosphorylation. Serum-starved HEK293 cells expressing the NPY Y $_{1}$ receptor were incubated for $5 \mathrm{~min}$ with increasing concentrations of NPY. (C) Serum-starved HEK293 cells expressing either the NPY $Y_{1}$ receptor were pre-treated with varying concentrations of PTX for $18 \mathrm{~h}$ followed by 5 min stimulation with NPY (100 nM). (D) Effect of increasing concentrations of MEK inhibitor U0126 on NPY-induced ERK1/2 activation. Serum-starved HEK293 cells expressing the NPY $Y_{1}$ receptor were pretreated with varying concentrations of $\mathrm{U} 0126$ for $1 \mathrm{~h}$ followed by 5 min stimulation with NPY (300 pM). Values are means \pm sem (where not seen, sem is too small to be visible) from 8-9 independent experiments 


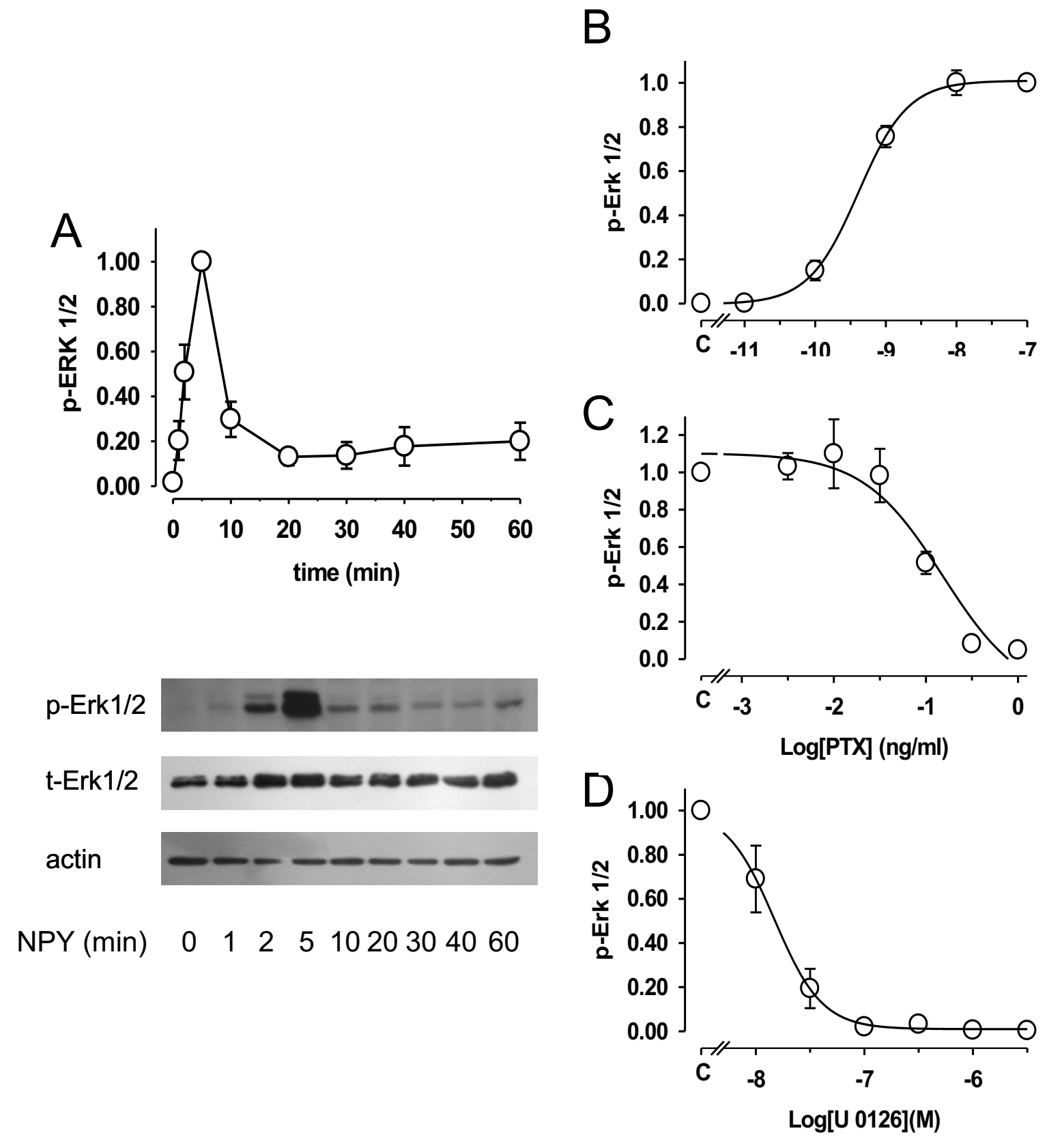

Figure 1 


\section{Figure 2}

Kinetics of NPY-induced ERK1/2 activation by NPY $Y_{2}$ receptor. (A) A representative western blot is displayed illustrating the lower intensities of the ERK1/2 activation by NPY $Y_{2}$ receptor as compared to activation by NPY $Y_{1}$ receptor. $20 \mu \mathrm{g}$ of total protein were analyzed. ERK1/2 phosphorylation was determined using anti-phospho-ERK1/2 antibody. Anti-total-ERK1/2 and anti-actin antibodies were used to control protein concentrations. (B) Time course of ERK1/2 phosphorylation following NPY stimulation in human $\mathrm{Y}_{2}(\bigcirc)$ receptors expressed in HEK293 cells. Serum-starved HEK293 cells were incubated with NPY (100 nM) for the indicated times, the densitometry analyses of ERK1/2 activation was normalized to the maximal response at 10 minutes. (C) Concentration-dependence of ERK1/2 phosphorylation. Serumstarved HEK293 cells expressing the NPY $Y_{2}$ receptor were incubated for 10 min with increasing concentrations of NPY. (D) Serum-starved HEK293 cells expressing either the NPY $\mathrm{Y}_{2}$ receptor were pre-treated with varying concentrations of PTX for $18 \mathrm{~h}$ followed by 10 min stimulation with NPY (100 nM). Shown are densitometry analyses of ERK1/2 activation from 4 to 8 independent experiments. 


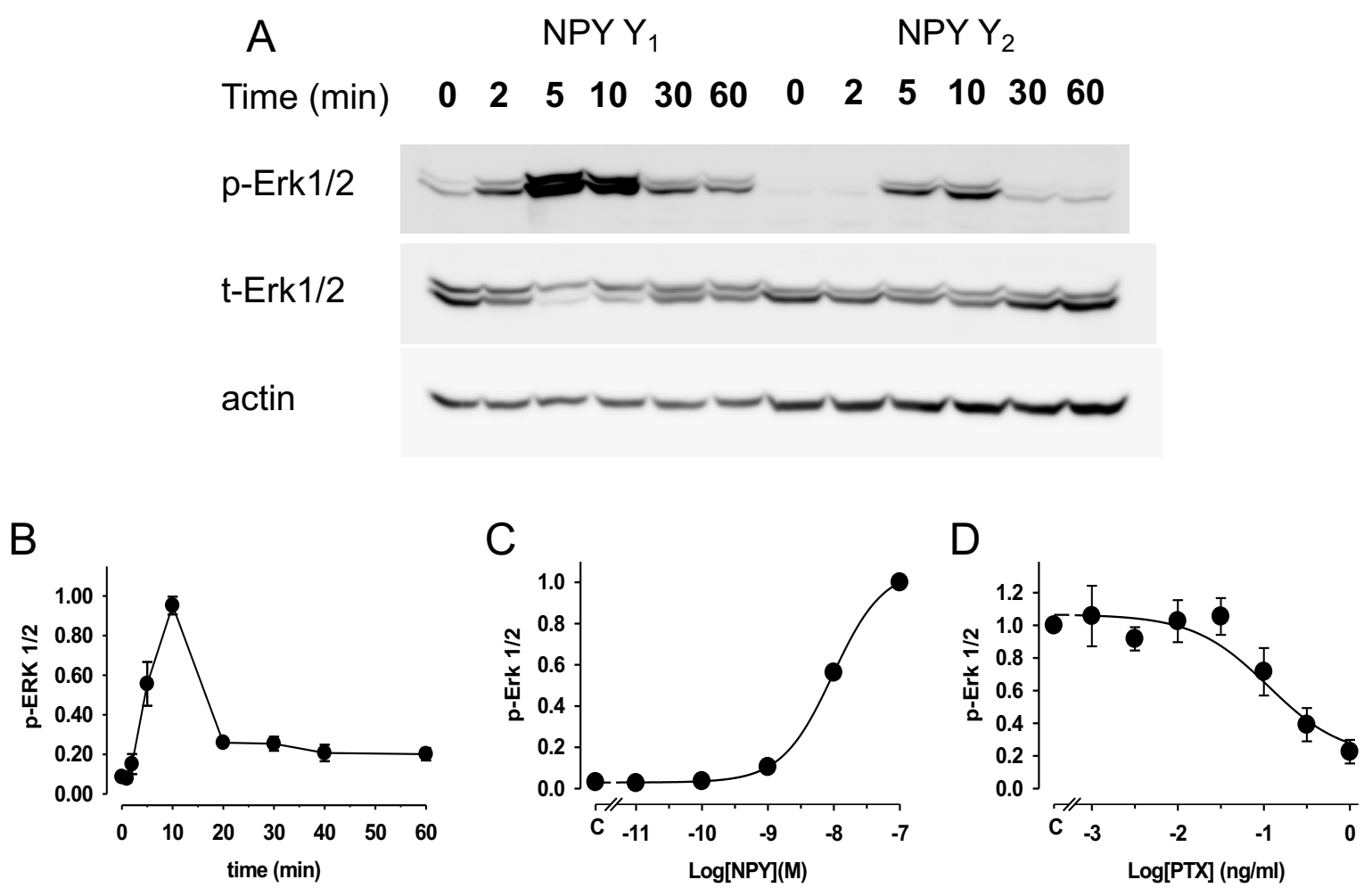

Figure 2

Figure 3

Concentration dependence of ERK1/2 phosphorylation of different mutants of the NPY $Y_{1}$ receptor. Time course of ERK1/2 phosphorylation following NPY stimulation in human $Y_{1} \Delta 42(A, \square)$ and $Y_{1}$ TDST-A $(B, \triangle)$. Serum-starved HEK293 cells expressing the different NPY receptors were incubated with 100nM NPY at different time points. Values are means \pm sem (where not seen, sem is too small to be visible) from 4 to 8 independent experiments. 

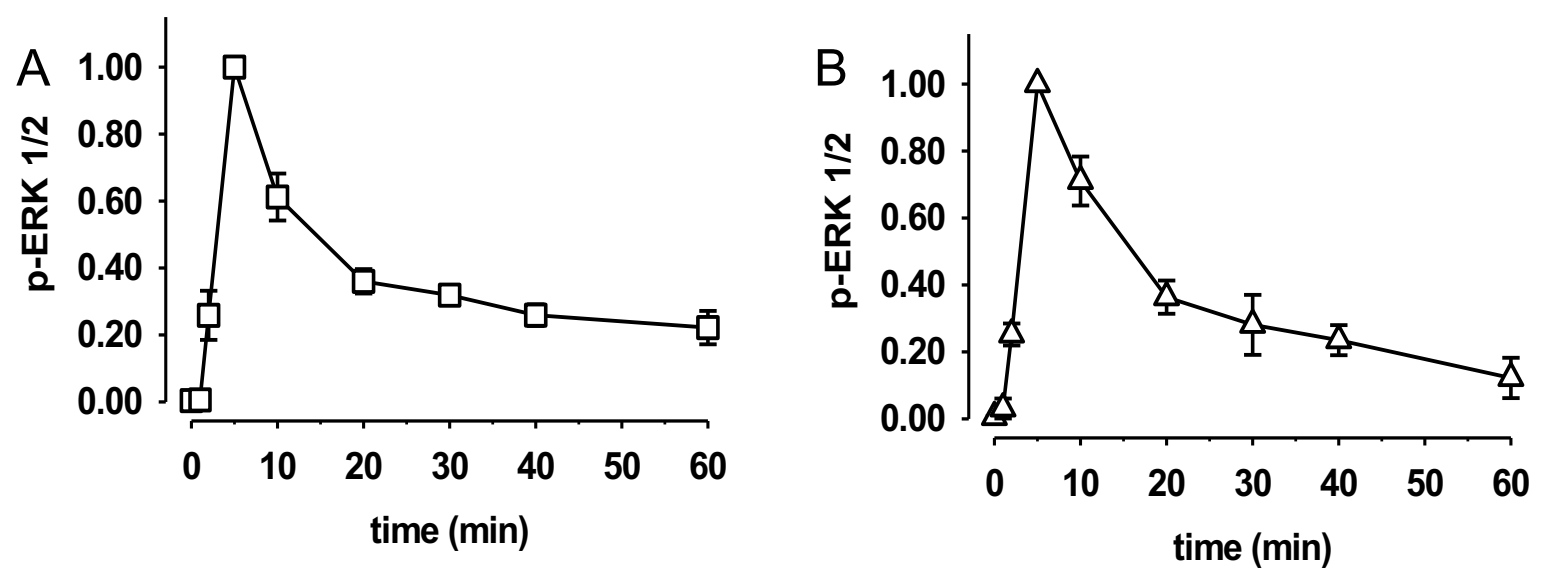

Figure 3

\section{Figure 4}

Effect of pre-treatment with various inhibitors on NPY Y1 receptor induced ERK1/2 activation.

Serum-starved HEK293 cells expressing the NPY $Y_{1}$ receptor were pre-treated with varying concentrations of U73112 (PLC inhibitor; A), of Gö6983 (PKC inhibitor, B), of gallein ( $G / \gamma$-dependent signalling, $C$ ), of the selective PI3K inhibitor wortmannin (D), of PP2 (Src-family tyrosine kinase inhibitor, E) and of AG1478, an EGFR tyrosine kinase inhibitor $(F)$ for $1 \mathrm{~h}$ followed by stimulation for 5 min with NPY (300 pM). Values are means \pm sem (where not seen, sem is too small to be visible) from $5-8$ independent experiments. 

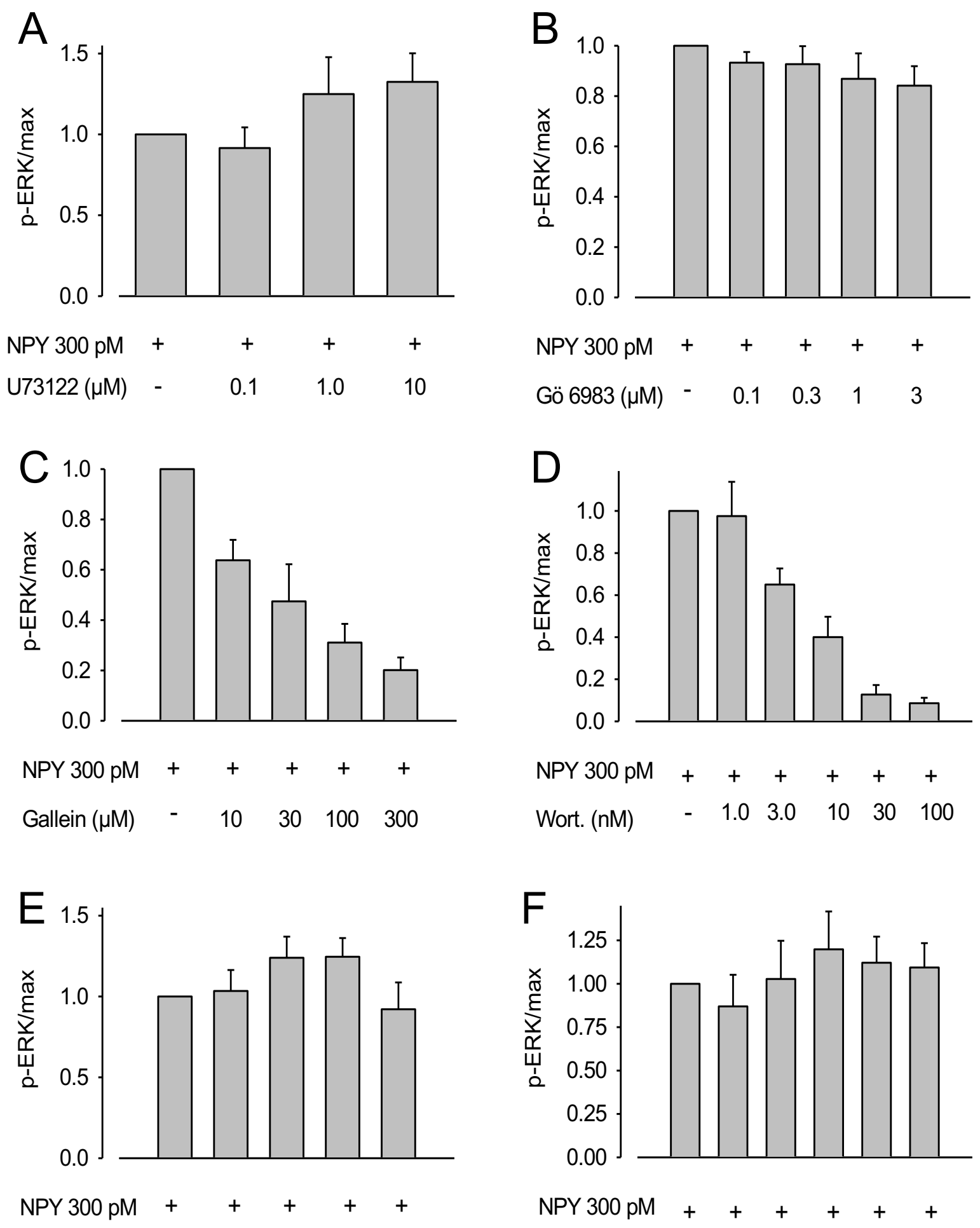
$\begin{array}{llllll}\mathrm{PP} 2(\mu \mathrm{M}) & - & 0.3 & 1.0 & 3.0 & 10\end{array}$

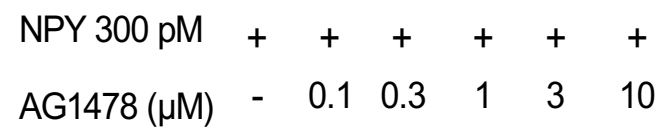

Figure 4 


\section{Figure 5}

NPY-mediated ERK1/2 activation is dependent on Insulin receptor tyrosine kinase function. Serum-starved HEK293 cells expressing the NPY $Y_{1}$ receptor were pretreated for $1 \mathrm{~h}$ with varying concentrations of AG1024 an IGFR tyrosine kinase inhibitor followed by $5 \mathrm{~min}$ stimulation with NPY (300 pM). In all blots, $20 \mu \mathrm{g}$ of total protein were analyzed. Shown are densitometry analyses of ERK1/2 activation. Values are means \pm sem from 6 independent experiments.

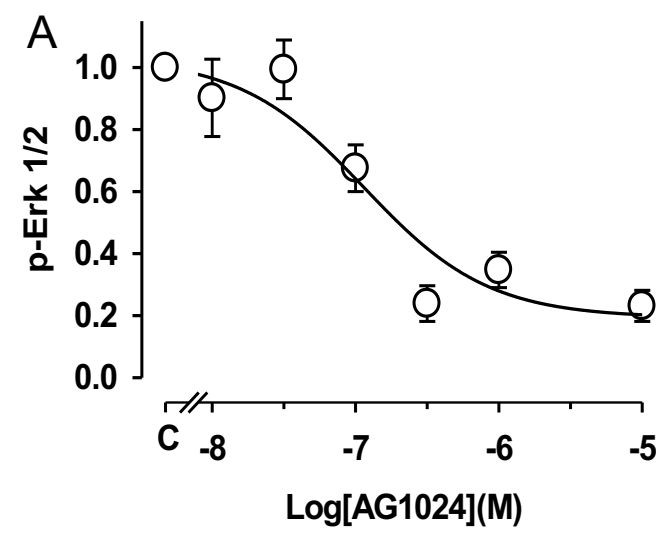

C p-Erk $1 / 2$

\section{$\mathrm{t}-\mathrm{Erk} 1 / 2$} actin

NPY 300 pM

Vehicle

AG1024 $10 \mu \mathrm{M}$

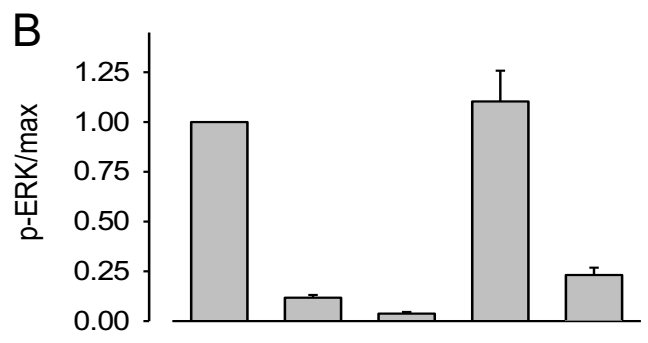

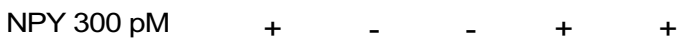

Vehicle

AG1024 $10 \mu \mathrm{M}$

D

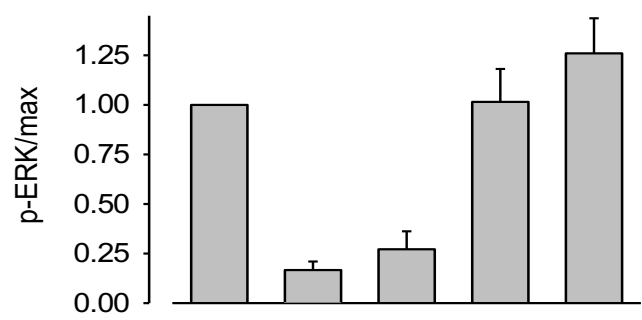

NPY 300 pM

Vehicle

Marimastat $10 \mu \mathrm{M}$

Figure 5 


\section{Figure 6}

ERK1/2 activation in HEK293 cells by several GPCRs is dependent on a wortmannin-AG1024-sensitive pathway. Representive westen blots of serum-starved HEK293 cells were pre-treated for $1 \mathrm{~h}$ with Wnt, AG1024 or marimastat followed by 5 min stimulation with AcethylCholine (Ach $1 \mu \mathrm{M}$, endogenous muscarinic $\mathrm{M} 3$ receptors, A, B, C respectively). Shown are densitometry analyses of ERK1/2 activation activated by muscarinic $M 3$ receptors $(D, E, F)$ or with agonist of the endogenous Endothelin $\mathrm{B}$ receptor (NECA, 30nM G, H, I respectively). Values are means \pm sem from 4 independent experiments.
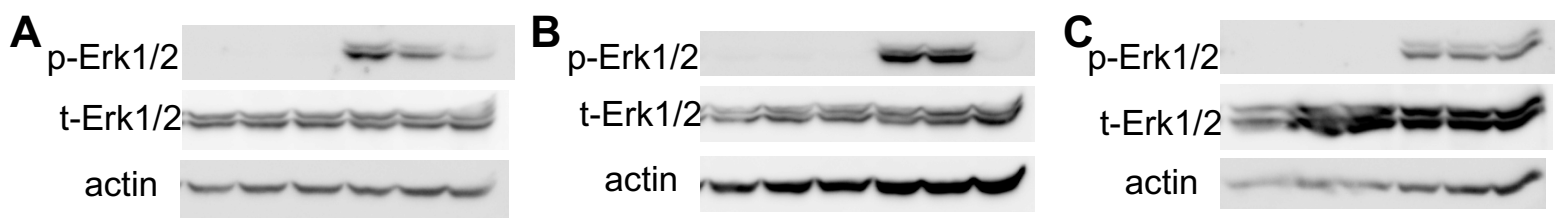

D
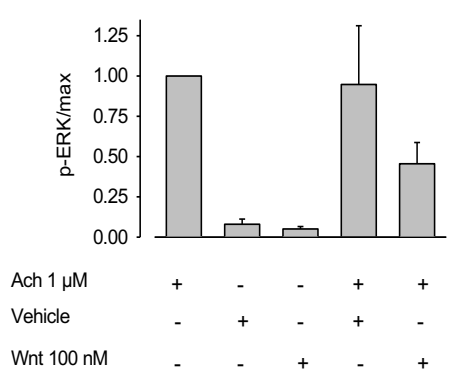

G

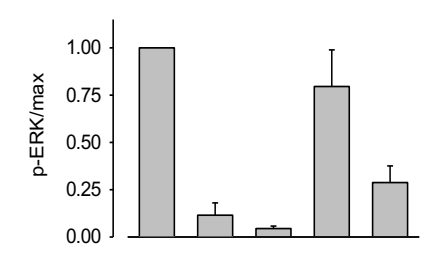

NECA 30nM

Vehicle

Wnt $100 \mathrm{nM}$

E

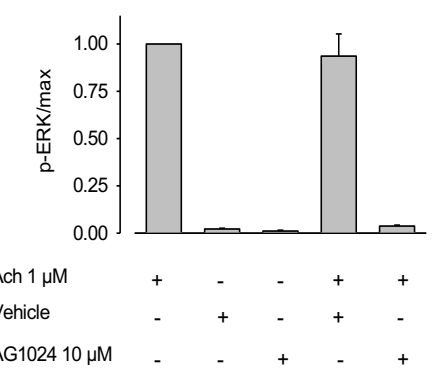

H

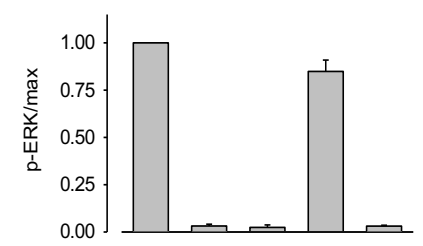

NECA 30nM

Vehicle

AG1024 $10 \mu \mathrm{M}$
F

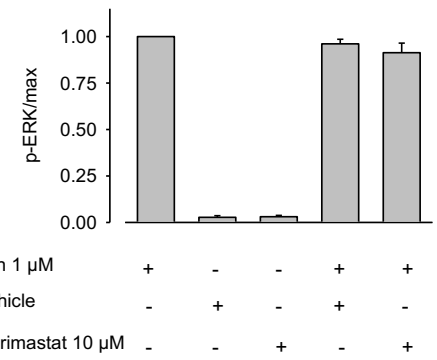

I

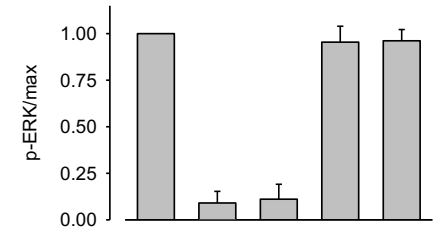

NECA 30nM

Vehicle

Marimastat $10 \mu \mathrm{M}$

Figure 6 